УдК: 519.872

Юрій Аркадійович Гусак (доктор військових наук, с.н.с.)

Ігор Іванович Шовкошитний (кандидат військових наук, с.н.с.)

Іван Михайлович Старинський

Центральний науково-дослідний інститут Збройних Сил України, Київ, Украӥна

\title{
МОДЕЛЮВАННЯ ДІЙ РАДІОЛОКАЦІЙНОЇ РОЗВІДКИ В КОМПЛЕКСНІЙ СИСТЕМІ ВИЯВЛЕННЯ БЕЗПІЛОТНИХ ЛІТАЛЬНИХ АПАРАТІВ
}

\begin{abstract}
У статті розглядається радіолокаџійний канал системи комплексної протидї безпілотним літальним апаратам (БпЛА) [4]. Як відомо, система комплексної протидї включає в себе засоби виявлення, а саме: засоби радіотехнічної та радіолокаційної розвідки, оптико-електронні, акустичні, тепловізійні засоби виявлення безпілотних літальних апаратів та пункти візуального спостереження, а також засоби ураження - станиії радіоелектронної боротьби, бойові лазерні системи та системи надпотужного надвисокочастотного випромінення, вогневі засоби ураження. Зазначені засоби створюють систему комплексної протидії безпілотним літальним апаратам. На прикладі радіолокаційного засобу виявлення (радіолокаційної станції) показано, яким чином можна формалізувати канали комплексного виявлення безпілотних літальних апаратів. Математична модель радіолокаційного виявлення побудована на основі марковської моделі «загибелі та розмноження».

Прочес виявлення та ідентифікації БпЛА представлено графом станів каналу радіолокаційного виявлення, на основі якого записано систему диференціальних рівнянь для ймовірності перебування каналу радіолокаційного виявлення у відповідних станах. Знайдені рімення системи диференціальних рівнянь у сталому режимі. Введені нові показники, а саме: приведена інтенсивність виявлення БпЛА та приведена інтенсивність правильного виявлення БпЛА (ідентифікації повітряної иілі як БпЛА). Показано, щзо приведена інтенсивність виявлення БпЛА залежить від ймовірності виявлення їх конкретним радіолокаційним засобом (радіолокаційною станцією), а приведена інтенсивність правильного виявлення БпЛА - від характеристик радіолокаційного засобу виявлення. Математична модель є універсальною та дає можливість отримати ймовірності виявлення БпЛА для будь-якого каналу виявлення.

У статті проведено аналіз залежності ймовірностей перебування каналу радіолокачійного виявлення від ефективної поверхні розсіювання (ЕПР) БпЛА та від дальності його виявлення. Наведені відповідні графіки та зроблено висновок про те, щзо математична модель адекватно описує проиес виявлення БпЛА радіолокаційним каналом.
\end{abstract}

Ключові слова: комплексна протидія БпЛА, модель масового обслуговування, радіолокащійні засоби.

\section{Вступ}

В умовах особливого періоду в країні, коли продовжуються бойові дії на сході України, виник конфлікт в Азовському морі, особлива увага має приділятися підвищенню якості підготовки військових фахівців різних рівнів. Це пояснюється тим, що складне озброєння і військову техніку (ОВТ) мають експлуатувати грамотні спеціалісти, які володіють достатніми теоретичними знаннями i практичними навичками, можуть приймати правильні рішення у проблемних ситуаціях.

Постановка проблеми. Аналіз досвіду сучасних війн і збройних конфліктів свідчить про стрімке зростання ролі БПЛА, сфери застосування яких, починаючи з другої половини ХХ сторіччя, значно розширились. Новітні безпілотні авіаційні комплекси стали невід'ємним елементом розвідувальних і розвідувально-ударних систем у війнах нинішнього покоління, однією 3 характерних рис якого вважається ведення безконтактних бойових дій 3 отриманням у реальному часі розвідувальної інформації та миттєвим завдаванням ударів по об'єктах. Постійне збільшення кількості та типів засобів безпілотної авіації зумовило необхідність проведення досліджень стосовно виявлення та боротьби з ними.

Основним засобом виявлення в сучасних системах протиповітряної оборони $\epsilon$ радіолокаційні станції. Вони здатні засікати літаки i вертольоти на відстані до декількох десятків кілометрів, залежно від характеристик цілі і особливостей місцевості. У ряді випадків БпЛА, особливо легкого класу, не завжди є ціллю для існуючих РЛС, оскільки ці апарати мають малу 
ЕПР, через що їх виявлення стає досить непростим завданням.

Комплексні дослідження щодо виявлення безпілотних авіаційних комплексів та протидії їм показали, що виявлення тактичних БпЛА $є$ складним завданням для більшості існуючих РЛС [1]-[2]. Одним із напрямів вирішення цієї проблеми $є$ розроблення сучасних радіолокаційних засобів на основі моделювання їх дій у комплексній системі виявлення БпЛА. Для цього необхідно розробити адекватну математичну модель, яка б давала можливість врахувати як характеристики БПЛА, так i характеристики радіолокаційних засобів їх виявлення.

Аналіз останніх досліджень і публікацій. Аналіз більшості праць [5]-[7], присвячених проблемним питанням виявлення БПЛА, свідчить про те, що нині розроблені та застосовуються підходи, які описують окремі способи виявлення БпЛА як об'єкта повітряного нападу. Однак немає наукових праць щодо процесу моделювання дій радіолокаційних засобів виявлення БпЛА в комплексній системі протидії їм.

За масштабом виконуваних завдань найбільш поширеними є БПЛА тактичного та оперативнотактичного призначення [2]; [3]. Саме ці типи БпЛА $є$ найбільш проблемними щодо їх своєчасного виявлення та знищення. За останні роки здійснюються активні пошуки ефективних способів та засобів боротьби із зазначеними типами літальних апаратів. Нині поки що таких засобів у військах немає, а виявлення БпЛА здійснюється тими радіолокаційними засобами, які $\epsilon$ в розпорядженні командування.

Особливостями БПЛА, як об'єктів для засобів радіолокаційної розвідки, є:

можливість польоту до об'єктів удару (розвідки) на гранично малих висотах, що ускладнює їх своєчасне виявлення, а також впливає на безперервність їх супроводження підрозділами РТВ та ЗРВ;

мала радіолокаційна помітність, яка зумовлена малою ЕПР, що також ускладнює своєчасне виявлення радіолокаційними засобами РТВ та ЗРB;

виявлення БпЛА відбувається в зоні засвічувань від місцевих предметів, що потребує включення апаратури захисту від пасивних завад.

\section{Виклад основного матеріалу}

\section{дослідження}

У роботі [4] запропоновано математичну модель комплексної протидії БпЛА, у якій розглядаються два етапи комплексної протидії виявлення та ураження. Так, на етапі виявлення застосовувалися засоби радіотехнічної та радіолокаційної розвідки, оптико-електронні, акустичні, тепловізійні засоби виявлення БпЛА та візуального спостереження тощо, а на етапі ураження - станції радіоелектронної боротьби, лазерні системи та системи надпотужного НВЧвипромінення, вогневі засоби тощо.

У зазначеній математичній моделі досліджувалися характеристики процесу виявлення БпЛА. Для цього було побудовано граф процесу комплексного виявлення БПЛА (рис. 1).

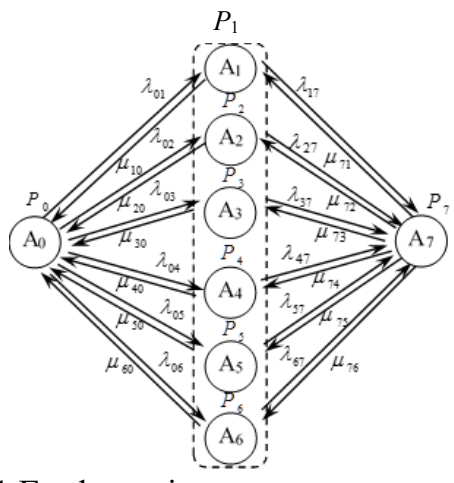

Рис.1 Граф станів системи комплексного виявлення БпЛА

де станам графа відповідають наступні події:

$\mathrm{A}_{0}$ - всі канали виявлення вільні, БПЛА немає;

$\mathrm{A}_{1}$ - БПЛА виявлено 1-м каналом;

$\mathrm{A}_{2}$ - БпЛА виявлено 2-м каналом;

$\ldots$

$\mathrm{A}_{6}$ - БпЛА виявлено 6-м каналом;

$\mathrm{A}_{7}$ - БПЛА ідентифіковано.

При цьому, $\lambda_{0}-$ інтенсивність появи БпЛА в зоні виявлення, а $\mu_{1}, \mu_{2}, \ldots, \mu_{6} є$ інтенсивностями обслуговування відповідного каналу виявлення БПЛА.

Розглянемо систему радіолокаційної розвідки, як окрему складову системи комплексного виявлення БпЛА.

Проаналізуємо модель радіолокаційного виявлення БпЛА. Для цього побудуємо граф станів системи радіолокаційного виявлення БпЛА (рис. 2), де стан $\mathrm{S}_{1}$ відповідає ситуації, коли БпЛА немає в межах зони виявлення засобу радіолокаційного виявлення повітряних цілей; стан $\mathrm{S}_{2}$ - ситуації, коли БпЛА перебуває у зоні виявлення і радіолокаційний засіб веде розвідку; стан $\mathrm{S}_{3}-$ ситуації, коли повітряну ціль ідентифіковано як БпЛА (рис. 2).

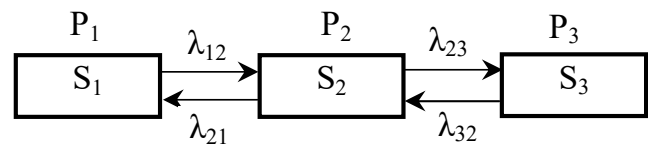

Рис. 2 Граф станів системи радіолокаційного виявлення БПЛА

Ймовірність перебування системи радіолокаційного виявлення у станах $\mathrm{S}_{\mathrm{k}}$, де $\mathrm{k}=\overline{1, \mathrm{n}}$, позначимо як $\mathrm{P}_{\mathrm{k}}(\mathrm{t})$.

Відповідно до графа станів (рис. 2) система диференціальних рівнянь для імовірностей перебування системи у відповідних станах має вигляд:

$$
\left\{\begin{array}{l}
\frac{d P_{1}}{d t}=-\lambda_{12} \mathrm{P}_{1}+\lambda_{21} \mathrm{P}_{2} \\
\frac{\mathrm{dP}}{\mathrm{dt}}=-\lambda_{21} \mathrm{P}_{2}-\lambda_{23} \mathrm{P}_{2}+\lambda_{12} \mathrm{P}_{1}+\lambda_{32} \mathrm{P}_{3} \\
\frac{\mathrm{dP}}{\mathrm{dt}}=\lambda_{23} \mathrm{P}_{2}-\lambda_{32} \mathrm{P}_{3}
\end{array},\right.
$$


де $\mathrm{P}_{1}, \ldots, \mathrm{P}_{3}$ - ймовірності перебування системи у станах $\mathrm{S}_{1}, \ldots, \mathrm{S}_{3}$ відповідно;

$\lambda_{12}$ - інтенсивності переходу системи зі стану $\mathrm{S} 1$ у стан $\mathrm{S}_{2}$;

$\lambda_{23}-$ інтенсивності переходу системи зі стану $\mathrm{S}_{2}$ у стан $\mathrm{S}_{3}$;

$\lambda_{21}$ - інтенсивності переходу системи зі стану $\mathrm{S}_{2}$ у стан $\mathrm{S}_{1}$;

$\lambda_{32}-$ інтенсивності переходу системи зі стану $\mathrm{S}_{3}$ у стан $\mathrm{S}_{2}$.

3 точки зору виявлення БПЛА, інтенсивність переходу системи зі стану $\mathrm{S}_{1}$ у стан $\mathrm{S}_{2}$ - це інтенсивність виявлення повітряної цілі РЛзасобом, яка описується виразом:

$$
\lambda_{12}=\frac{1}{\mathrm{t}_{12}} \mathrm{P}_{12},
$$

де $\mathrm{P}_{12}$ - ймовірність виявлення повітряної цілі РЛ-засобом;

$\overline{t_{12}}-$ середній час виявлення повітряної цілі РЛ- засобом.

Інтенсивність переходу системи зі стану $\mathrm{S}_{2} \mathrm{y}$ стан $\mathrm{S}_{3}-$ це інтенсивність правильного виявлення повітряної цілі як БпЛА, яка описується виразом:

$$
\lambda_{23}=\frac{1}{\mathrm{t}_{23}} \mathrm{P}_{23},
$$

де $\mathrm{P}_{23}$ - ймовірність правильного виявлення повітряної цілі РЛ-засобом як БпЛА;

$\overline{\mathrm{t}_{23}}$ - середній час правильного виявлення повітряної цілі в каналі РЛ-виявлення.

Інтенсивність переходу системи зі стану $\mathrm{S}_{3}$ y стан $\mathrm{S}_{2}$ - це інтенсивність правильного не виявлення повітряної цілі, яка описується виразом:

$$
\lambda_{32}=\frac{1}{\mathrm{t}_{32}} \mathrm{P}_{32}
$$

де $\mathrm{P}_{32}=1-\mathrm{P}_{23}-$ ймовірність правильного не виявлення оператором повітряної цілі як такої, що не належить до БпЛА;

$\overline{t_{32}}$ - середній час правильного не виявлення повітряної цілі як такої, що не належить до БпЛА.

Інтенсивність переходу системи зі стану $\mathrm{S}_{2} \mathrm{y}$ стан $\mathrm{S}_{1}$ - це інтенсивність того, що повітряна ціль не буде виявлена РЛ-каналом, яка описується виразом:

$$
\lambda_{21}=\frac{1}{\overline{\mathrm{t}_{21}}} \mathrm{P}_{21},
$$

де $\mathrm{P}_{21}=1-\mathrm{P}_{12}-$ ймовірність не виявлення повітряної цілі РЛ-засобом;

$\overline{\mathrm{t}_{21}}-$ середній час перебування повітряної цілі у зоні виявлення РЛ-засобу.

Відповідно до [8] ймовірність виявлення повітряної цілі $\mathrm{P}_{12}(\mathrm{D})$ залежно від дальності (D) описується наступним виразом:

$$
\mathrm{P}_{12}(\mathrm{D})=\mathrm{e}^{-\left(\frac{\mathrm{D}}{\mathrm{D}_{0}}\right)^{4}}
$$

де $\mathrm{D}_{0}=\mathrm{f}\left(\sigma_{\text {ц }}\right)$ - функція, яка описує залежність дальності виявлення повітряної цілі РЛ-засобом від ЕПР повітряної цілі $\left(\sigma_{ц}\right)$.

Введемо:

показник приведеної інтенсивності виявлення повітряної цілі РЛ-засобом:

$$
\alpha_{1}=\frac{\lambda_{12}}{\lambda_{21}}=\frac{\mathrm{P}_{12}}{\mathrm{P}_{21}}=\frac{\mathrm{P}_{12}}{1-\mathrm{P}_{12}},
$$

показник приведеної інтенсивності правильного виявлення повітряної цілі РЛзасобом:

$$
\alpha_{2}=\frac{\lambda_{23}}{\lambda_{32}}=\frac{\mathrm{P}_{23}}{\mathrm{P}_{32}}=\frac{\mathrm{P}_{23}}{1-\mathrm{P}_{23}},
$$

Відповідно до [9] рішенням системи диференціальних рівнянь (1) 3 урахуванням виразів (7) та (8) є:

$$
\left\{\begin{array}{l}
\mathrm{P}_{1}=\frac{1}{1+\alpha_{1}\left(1+\alpha_{2}\right)} \\
\mathrm{P}_{2}=\alpha_{1} \mathrm{P}_{1} \\
\mathrm{P}_{3}=\alpha_{1} \alpha_{2} \mathrm{P}_{1}
\end{array}\right.
$$

$\mathrm{P}_{1}$ - ймовірність того, що повітряної цілі немає в зоні виявлення радіолокаційного засобу;

$\mathrm{P}_{2}$ - ймовірність того, що повітряна ціль виявлена радіолокаційним засобом;

$\mathrm{P}_{3}$ - ймовірність того, що повітряна ціль правильно виявлена (ідентифікована) як БпЛА.

Відповідно до [10] можемо записати вираз ймовірності правильного виявлення повітряної цілі:

$$
\mathrm{P}_{\text {Пв }}=\frac{1}{2}\left[1+\Phi\left(v \sqrt{\frac{\mathrm{N}_{\mathrm{i}}}{2}-\frac{\ln \lambda_{\text {пор }}}{v \sqrt{2 \mathrm{~N}_{\mathrm{i}}}}}\right)\right],
$$

де $\Phi$ - інтеграл ймовірності;

$v=\mathrm{P}_{\mathrm{c}} / \mathrm{P}_{\mathrm{m}}-$ відношення потужності сигналу до потужності шуму на виході лінійної частоти приймача;

$\lambda_{\text {пор }}-$ порогове значення відношення правдоподібності;

$\mathrm{N}_{\mathrm{i}}=\mathrm{F}_{\mathrm{i}} \varphi_{0,5} / 6 \mathrm{n}_{\mathrm{A}}-$ число обробляючих імпульсів цілі, де $\varphi_{0,5}$ - ширина діаграми направленості на рівні половини потужності та $\mathrm{n}_{\mathrm{A}}$ - швидкість обертання антени (об/хв).

Основна формула для визначення максимальної дальності виявлення повітряної цілі РЛ-засобом виглядає наступним чином [10]:

$$
\begin{aligned}
& \mathrm{D}_{\max }=\mathrm{D}_{0}=\sqrt[4]{\frac{\mathrm{P}_{\text {пер }} \mathrm{G}_{\text {max }} \mathrm{S}_{\mathrm{A}} \sigma_{\text {ц }}}{16 \pi^{2} \mathrm{P}_{\text {пр.мін }}^{\prime} v_{\mathrm{p}}}}=\sqrt[4]{\gamma \sigma_{\text {ц }}}, \\
& \text { де } \gamma=\frac{\mathrm{P}_{\text {пер }} \mathrm{G}_{\text {max }} \mathrm{S}_{\mathrm{A}}}{16 \pi^{2} \mathrm{P}_{\text {пр.мін }}^{\prime} \mathrm{v}_{\mathrm{p}}}-\text { коефіцієнт, який має одне }
\end{aligned}
$$

значення для конкретного РЛ-засобу; 
$\mathrm{P}_{\text {пер }}$ - потужність, випромінювана передавачем;

$\mathrm{P}_{\text {пр.мін }}^{\prime}$ - гранична чутливість приймача;

$\mathrm{G}_{\max }$ - максимальний коефіцієнт направленої дії антени;

$\mathrm{S}_{\mathrm{A}}$ - ефективна площа антени;

$\sigma_{\text {ц }}$ - ефективна відбиваюча площа цілі;

$v_{\mathrm{p}}$ - коефіцієнт розрізнення.

Відповідно до виразу (10) знайдемо ймовірність правильного виявлення повітряної цілі для РЛС X1-М “Око” (табл. 1) [1]:

$$
\mathrm{P}_{\text {Пв }}=\frac{1}{2}\left[1+\Phi\left(1,5 \sqrt{\frac{25}{2}-\frac{\ln 1,5}{1,5 \sqrt{50}}}\right)\right]
$$

Таблиця 1

Можливості РЛС Х1-М “Око” з виявлення маловисотних малорозмірних цілей

\begin{tabular}{|c|c|c|c|c|c|}
\hline \multirow{2}{*}{ Тип } & \multicolumn{5}{|c|}{$\begin{array}{c}\text { Дальність виявлення повітряних цілей з ЕПР } \\
1 \text { м2 (0,3 м2; 0,1 м2) на малих висотах, км }\end{array}$} \\
\hline & $\mathrm{Hц}=100 \mathrm{M}$ & $\mathrm{H} \leftrightharpoons=300 \mathrm{M}$ & $\mathrm{Hц}=500 \mathrm{M}$ & $\mathrm{H}=1000 \mathrm{M}$ & $\mathrm{H}=4000 \mathrm{M}$ \\
\hline $\begin{array}{l}\text { X1-М } \\
\text { "Око" }\end{array}$ & $-(-; 4,2)$ & $-(-; 5)$ & $-(-; 5,5)$ & $-(-; 6)$ & $\begin{array}{l}\text { даних } \\
\text { немає }\end{array}$ \\
\hline
\end{tabular}

Підставивши значення $\mathrm{P}_{\text {Пв }}$ у вираз (8), визначимо показник приведеної інтенсивності правильного виявлення повітряної цілі РЛзасобом:

$$
\alpha_{2}=\frac{P_{23}}{1-P_{23}}=\frac{0,75}{1-0,75}=3 .
$$

Якщо підставити у вираз (6) значення максимальної дальності дії РЛС (табл. 2), то можна побудувати графіки залежності ймовірності виявлення БПЛА від дальності та ЕПР БПЛА (рис. 3).

Таблиця 2

Характеристики розсіювання (ЕПР) деяких типів БпЛА, отримані за результатами моделювання, а

\begin{tabular}{|c|c|c|c|c|c|}
\hline \multirow{2}{*}{$\begin{array}{l}\text { № } \\
\text { 3/ח }\end{array}$} & \multirow{2}{*}{$\begin{array}{c}\text { Тип } \\
\text { БпЛА }\end{array}$} & \multicolumn{2}{|c|}{$\begin{array}{c}\text { Кругова медіана } \\
\text { ЕПР, м2 } \\
\end{array}$} & \multirow{2}{*}{$\mathrm{D}_{\max _{\mathrm{M}}}$} & \multirow{2}{*}{$\begin{array}{c}\text { Приблизні } \\
\text { аналоги }\end{array}$} \\
\hline & & cM & дм & & \\
\hline 1. & Орлан-10 & 0,03 & 0,05 & 5477 & $\begin{array}{l}\text { "Гранат-4", } \\
\text { "Карнивора", } \\
\text { "Skylark-3", } \\
\text { "Hero-400" }\end{array}$ \\
\hline 2. & Форпост & $0,1-0,11$ & 0,11 & 7401 & $\begin{array}{l}\text { "RQ-7 Shadow", } \\
\text { "Kopcap", } \\
\text { "RQ-2 Pioneer", } \\
\text { "Hermes-90", } \\
\text { "Aerostar", } \\
\text { "Sperwer B", } \\
\text { "CH-3" }\end{array}$ \\
\hline 3. & Оріон & $0,97-0,05$ & 0,67 & 13161 & $\begin{array}{l}\text { "Hermes 900", } \\
\text { MQ-1 "Reaper", } \\
\text { MQ-1C } \\
\text { "GreyEagle", } \\
\text { "Дозор-600”, } \\
\text { "СН-4" }\end{array}$ \\
\hline
\end{tabular}
також значення $\mathrm{D}_{\max }$ для РЛС X1-М “Око” [1]

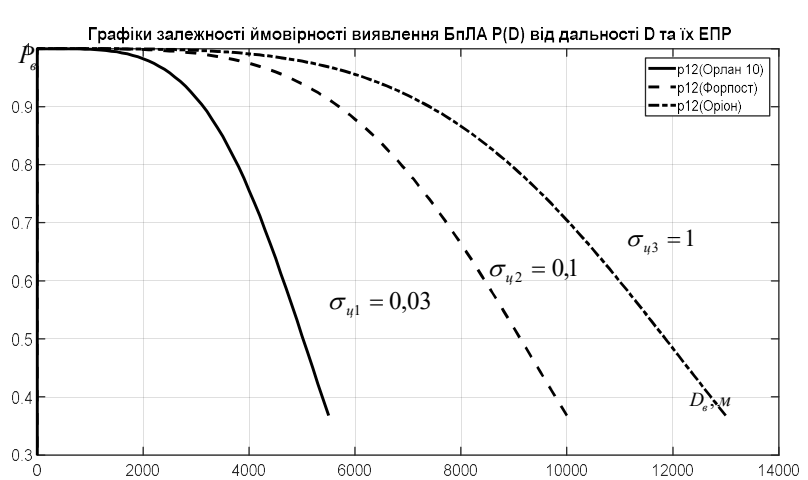

Рис. 3. Графіки залежності ймовірності виявлення БпЛА P(D) від дальності D та їх $\operatorname{EПP}\left(\sigma_{ц}\right)$

Результати моделювання дій радіолокаційного каналу виявлення на базі РЛС Х1-М “Око" в системі комплексного виявлення безпілотних літальних апаратів відображені на рис. 4-6.

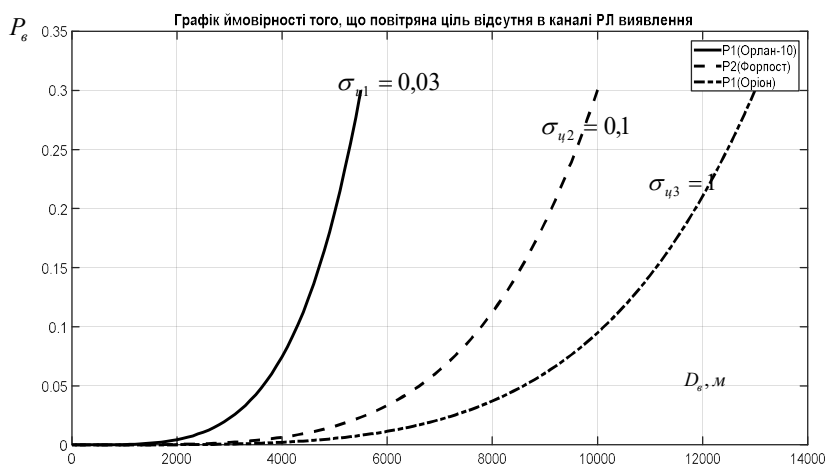

Рис.4. Графік ймовірності того, що повітряної цілі немає в каналі РЛ-виявлення

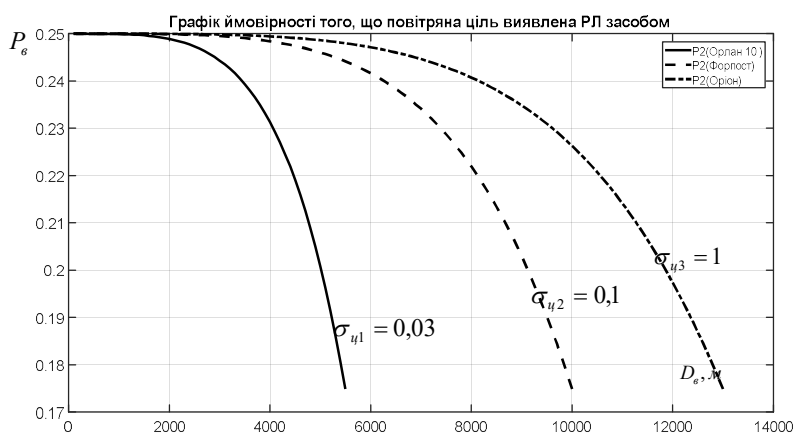

Рис. 5. Графік ймовірності того, що повітряна ціль виявлена РЛ-засобом

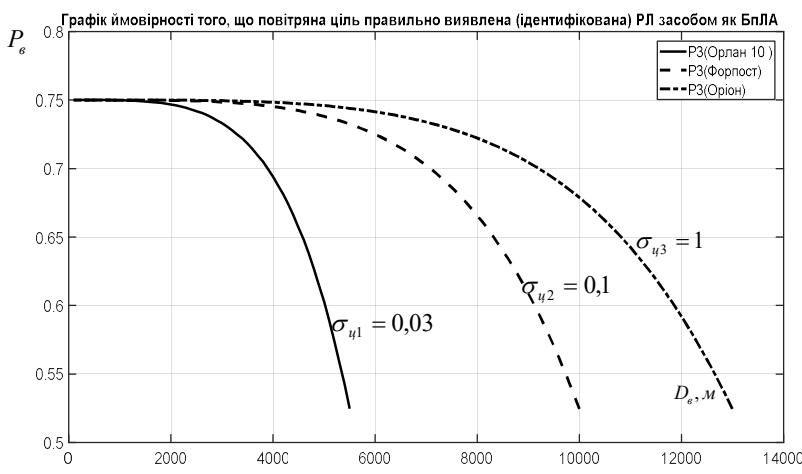

Рис. 6 Графік ймовірності того, що повітряна ціль правильно виявлена (ідентифікована) РЛ-засобом як БПЛА 
Аналіз графіків на рис. 3-6 показує, що запропонована математична модель виявлення БпЛА засобами РЛ-розвідки адекватно та очікувано реагує на зміну вхідних параметрів значень ЕПР цілі.

\section{Висновки і перспективи подальших досліджень}

Таким чином, розроблена математична модель радіолокаційного виявлення БпЛА адекватно описує процес функціонування засобів радіолокаційної розвідки та дає можливість оцінювати ймовірності перебування радіолокаційного каналу комплексної системи протидії БпЛА в тому чи іншому стані залежно від ЕПР цілі, а також технічних характеристик радіолокаційного засобу виявлення БпЛА.

Перспективами подальших досліджень $€$ використання даної моделі виявлення разом 3 іншими складовими системи виявлення БпЛА, які зазначалися вище.

\title{
Jimepamypa
}

1. Аналіз можливостей наявної системи протидії безпілотним літальним апаратам противника: звіт про НДР шифр "Градієнт” (проміж.) / ЦНДІ ЗС України. 2019. 248 с. Інв. № 17992. 2. Звіт про результати досліджень на навчаннях на тему: "Визначення можливостей наявних та перспективних засобів виявлення та протидії (ураження) безпілотних авіаційних комплексів та застосування ударних безпілотних літальних апаратів". Київ: ВНУ ГШ ЗС України, 2017.127 с. 3. Шуенкин В. А., Донченко В. С. Прикладные модели теории массового обслуживания. В помощь студентам специальности "Прикладная математика": учебн. пособ. Київ: НМК ВО, 1992. 398 с. 4. Гусак Ю. А., Старинський I. М. Математична модель комплексної протидії безпілотним літальним апаратам // Зб. наук. пр. ЦНДІ ЗС України. Київ. 2019. № 3 (89). C. 243-251. 5. Теорія i практика боротьби 3 малорозмірними низьколітними цілями (оцінка можливостей, тенденцій розвитку засобів протиповітряної оборони): моногр. / І.С.Романченко,
О. М. Загорка, С. Г. Бутенко, О. В. Дейнега. Житомир: Полісся, 2011. 344 с. 6. Про затвердження Концепції створення системи комплексної протидії безпілотним авіаційним комплексам противника від 10.04.2017 № 884/c/дск: Наказ начальника Генерального штабу Збройних Сил України. Київ. 2017. 14 с. 7. Даник Ю. Г. Аналіз ефективності виявлення тактичних безпілотних літальних апаратів пасивними та активними засобами спостереження // Збірник наукових праць ЖВІ ДУТ, 2015. Вип. 10. С. 5-20. 8. Справочник офицера противовоздушной обороны / под ред. Г. Зимина. Москва: Воениздат, 1981. 431 с. 9. Вентцель Е. С. Исследование операции: задачи, принципы, методология. - 2-е изд., стер. - Москва: Наука. Гл. ред. физ.-мат. лит., 1988. 208 с. (Пробл. науки и техн. прогресса). 10. Справочник по основам радиолокационной техники / под ред. В. В. Дружинина. - Москва: Воениздат, 1967. 768 с.

\section{МОДЕЛИРОВАНИЕ ДЕЙСТВИЙ РАДИОЛОКАЦИОННОЙ РАЗВЕДКИ В КОМПЛЕКСНОЙ СИСТЕМЕ ОБНАРУЖЕНИЯ БЕСПИЛОТНЫХ ЛЕТАТЕЛЬНЫХ АППАРАТОВ}

\author{
Юрий Аркадьевич Гусак (доктор военных наук, с.н.с.) \\ Игорь Иванович Шовкочитний (кандидат военных наук, с.н.с.) \\ Иван Михайлович Старинский
}

\section{Центральный научно-исследовательский институт Вооруженных Сил Украины, Киев, Украина}

В статье рассматривается радиолокационный канал системы комплексного противодействия беспилотным летательным аппаратам [4]. Как известно, система комплексного противодействия включает в себя средства обнаружения, а именно: средства радиотехнической и радиолокационной разведки, оптико-электронные, акустические, тепловизионные средства обнаружения беспилотных летательных аппаратов и пункты визуального наблюдения, а также средства поражения - станиии радиоэлектронной борьбы, боевые лазерные системы и системы сверхмощного СВЧ-излучения, огневые средства поражения. Указанные средства создают систему комплексного противодействия беспилотным летательным аппаратам. На примере радиолокационного средства обнаружения (радиолокационной станции) показано, каким образом можно формализовать каналь комплексного обнаружения беспилотных летательных аппаратов. Математическая модель радиолокационного обнаружения построена на основе марковской модели “гибели и размножения”.

Прочесс выявления и идентификации БпЛА представлен графом состояний канала радиолокационного обнаружения, на основе которого записано систему дифференциальных уравнений для вероятности пребывания канала радиолокационного обнаружения в соответствуюших состояниях. Найдены решения системы дифференщиальных уравнений в установившемся режиме. Введены новые показатели, а именно: приведенная интенсивность обнаружения БпЛА и приведенная интенсивность правильного обнаружения БпЛА (идентификации воздушной иеели как БпЛА). Показано, что приведенная интенсивность обнаружения БпЛА зависит от вероятности обнаружения их конкретным радиолокационным средством (радиолокационной станцией), а приведенная интенсивность правильного обнаружения БпЛА - от характеристик радиолокационного средства обнаружения. Математическая 
модель является универсальной и дает возможность получить вероятности обнаружения БпЛА для любого канала обнаружения.

В статье проведен анализ зависимости вероятности пребывания канала радиолокационного обнаружения от эффективной поверхности рассеивания (ЭПР) БпЛА и от дальности его обнаружения. Приведены соответствующие графики и сделан вывод о том, что математическая модель адекватно описывает процесс обнаружения БпЛА радиолокационным каналом.

Ключевые слова: комплексное противодействие беспилотным летательным аппаратам, модель массового обслуживания, радиолокационнье средства.

\title{
THE ACTION SIMULATION OF RADAR INTELLIGENCE IN A COMPLEX SYSTEM THE DISCOVERY OF UNMANNED AERIAL VEHICLES
}

\author{
Yurii Husak (Doctor of Military Sciences, Senior Researcher) \\ Ihor Shovkoshytnyi (Candidate of Technical Sciences, Senior Researcher) \\ Ivan Starynskyi
}

\section{Central Scientific Research Institute of the Armed Forces of Ukraine, Kyiv, Ukraine}

The article discusses radar channel system integrated counter unmanned aerial vehicles [4]. As it is known, the system of complex counter includes a detection means, namely the means of radio and radar reconnaissance, electro-optical, acoustic, thermal means of detecting unmanned aerial vehicles, and paragraphs visual observation and weapons stations warfare, military laser system and heavy duty microwave radiation, firepower destruction. These means create an integrated counter unmanned aerial vehicles. For example, radar detection (radar) shows how to formalize the complex detection of unmanned aerial vehicles. A mathematical model of the radar detection is constructed based on Markov model "death and reproduction".

The process of detection and identification the UAV is represented by the state graph of the channel radar detection, based on which the written system of differential equations for the probability of stay of the channel radar detection in the respective states. Found solution of the system of differential equations in the steady state. Introduced new indicators, namely: the intensity of the detecting UAV and the intensity of the correct detection of the UAV (identify aerial targets like UAVs). It is shown that the intensity of detection of the $U A V$ depends on the probability of discovery their particular means radar (radar station), and given the intensity of the correct detection of the UAV from the characteristics of the radar detection means. A mathematical model is universal and allows to obtain the probability of detection of the UAV for any channel detection.

In the article the analysis of the dependence of the probability of staging of the channel radar detection from the effective surface scattering (ESS) of the UAV and the range of detection. His given the corresponding graphs and it is concluded that the mathematical model adequately describes the discovery process of the UAV radar channel.

Key words: integrated UAV counteraction, queuing model, radar means.

\section{References}

1. Analysis of the capacity of the existing system to counter unmanned aerial vehicles of the enemy: a report on research code "Gradient" (interm.) / CSRI of the Armed Forces of Ukraine. 2019. 248 p. inv. 17992. 2. A report about research on the trening of on the teachings on the theme: "identifying opportunities for existing and prospective means of detection and reaction (destruction) of unmanned aircraft systems and applications of attack unmanned aerial vehicles". Kyiv: Scientific Department of the General staff of armed forces of Ukraine, 2017. 127 p. 3. Shuyenkin V. A., Donchenko V. S. Application of the model of the Queuing theory. To help for students specialty "Applied mathematics": teaching manual. Kyiv: NMK VO 1992. 398 p. 4. Gusak, Y. A., Starynskyi, I. M. Mathematical model of an integrated counteraction unmanned aerial vehicles // Coll. of scienc. worksof CSRI of the Armed Forces of Ukraine, Kyiv, No. 3 (89) pp. 243-251. 5. Theory and practice of struggle against against small-size low altitude targets (the assessment of opportunities, trends in the development of air defense): monograph. / I. S. Romanchenko, A. M. Zagorka, S. G. Butenko, A. V. Deynega. Zhitomir: Polesie. 2011. 344 p. 6. On approval of the Concept of an integrated system to counter unmanned aviation systems of the enemy from 10.04.2017 No. 884/S/DSK: the order of the chief of the General staff of the Armed Forces of Ukraine: Kyiv, 2017. 14 p. 7. Danik Yu. G. Analysis of the efficiency of tactical unmanned aerial vehicles detection by passive and active observation observation means / Collection of scientific works ZhVI DUT, 2015. Vol. 10. P. 5-20. 8. Air defence officer's reference book, ed. by G. Zimin. Moscow: Voenizdat, Military Publishing, 1981. 431 p.

9. Ventzel E. S. Investigation of operations: problems, principles, methodology. 2nd ed. Moscow: Nauka. Main. Ed. Of Phys. - math. lit 1988. - 208 p. (Problems of science and Techn. progress). 10. A reference book to the fundamentals of radar technology / edited by V. V. Druzhinin. - Moscow: Voenizdat, 1967. 768 p. 